\title{
The Impact of Spatial Externalities on the Economic Convergence in the Euro Mediterranean Countries
}

\author{
Amina NACEUR SBOUI \\ Faculty of economic sciences, Tunis El Manar University, Tunisia \\ Tel: 216- 97-439-064 E-mail: naceuramina@yahoo.fr \\ Mohamed Amine HAMMAS \\ Faculty of Economic Sciences of Sousse, Tunisia \\ Tel: 216 -22 -416- $443 \quad$ E-mail: hammasamine@yahoo.fr
}

\begin{abstract}
Recent models of economic growth have underlined the importance of external effects on the accumulation of factors of production (ROMER 1986, 1990; LUCAS 1988). The technology knowledge rises with stock of factors of production (human capital, physical capital, $\mathrm{R} \& \mathrm{D}$, etc.) to which all the producers contribute with identical manner. The idea is that the knowledge is considered as a free good and spread in entire economy. However, this new approach brings more explanation of economic growth; but it doesn't integrate the spatial dimension of these externalities.
\end{abstract}

In this paper, the analysis that we wish to present aims to demonstrate that the external effects on the accumulation of factors of production have a geographic dimension and they affect the regional convergence.

Adopting this new hypothesis, we derive an equation of convergence with external effects issue from the Mankiw, Romer \& Weil (1992) model, and we propose to estimate it with the recent methods of spatial econometrics to test the presence of these externalities and to estimate their effects on the economic convergence.

For the empirical validation, relying on a panel of 26 euro Mediterranean countries over the period 1995-2004, and using the matrix of distance and the matrix of contiguity to measure the interactions between these countries, we estimate the equation of convergence with spatial externalities derived from the model of Mankiw, Romer \& Weil (1992).

The results of estimation based on the integration of spatial dimension of externalities permit to appreciate better than the a-spatial growth theory, the effects of these externalities on the economic convergence in the case of economic integration in space. They allow to quantify a double effect of geographic spillovers and to valid the hypothesis that taking account of spatial externalities doesn't necessarily reduce the divergence between the North and the South Mediterranean countries. The reason of the persistence of this divergence is related to the absence of efficient interactions and coordination between these countries.

Keywords: External effects, Economic convergence, Spatial econometrics, Economic integration

\section{Introduction}

Recent models of endogenous growth have considered the importance of external effects on the accumulation of factor of production. A first approach (Romer, 1986; Lucas, 1988) tries to endogenous the technology by the "Marshallien externalities" on the stock of knowledge. The introduction of apprenticeship effects "learning by doing" permit to do of the knowledge a factor of production supplementary and to consider it as a joint output. The external effect proceeds from accrue of knowledge due to the increase of total stock of capital. Considered as a free good, meaning not perfectly appropriated by the producer, the knowledge is accessible freely and profit theoretically for all with the same manner.

A second approach (Romer, 1990; Aghion and Howitt, 1990) models explicitly the sector of research and its effects on the deepening of the technology innovation. The progress of technology proceeds then from a "production of technology" realised with a specialised activity of "R\&D" which is distinct from the production: 
- A first externality proceeds from the sector of « $R \& D »$ : each researcher has potentially to accede to the stock of accumulated knowledge in this sector for his own research.

- A second externality proceeds from the sector of production: with baying the intermediate goods, agents profit not only from this capital, but also from the increase of the technology incorporated in these goods of production.

These two explanations of technology progress, based on endogenous accumulation of knowledge, beget theoretically increasing returns to scale in the global level which can engender endogenous growth.

However, although this contribution, the theory of endogenous growth remains limited. Especially, because it doesn't takes into account of spatial dimension of these externalities and their role in explaining issues such as growth and economic convergence.

In this sense, the conjoint development of New Geographic Economy and the endogenous growth models in the 1990 years, have permit for economists to propose more appropriate approaches of problematic "innovation-localisation-growth" (Foray, 2000).

Essentially, the theoretical models of "New Geographic Economy-Endogenous Growth" (C.Baumont, 1995) support on the hypothesis of geographic dimension of externalities of knowledge for explaining the specificity of phenomenon of spatial concentration of innovation and dynamics of differentiated growth that proceeds.

Until the middle of 1990 years, this hypothesis hasn't any empirical validation. Thus, only lately those empirical studies had proposed to integrate the effects of spatial externalities on the regional growth (Amstrong, 1995; Rey and Montouri, 1999; López-Bazo et al, 1999). Their suggestions are consistent with predictions of endogenous growth models and new geographic economy that insist on the role of interactions between agents which are considered as the sources of agglomerations of activities of innovation in some regions and not in others (Fujita et al, 1999).

On this base, in our present work we consider that the external effects on the accumulation of factors of production (human capital and physical capital) are geographically burned and they influence the economic convergence.

For verifying it empirically, we privilege the methods of spatial econometrics which constitute a powerful tool to test the presence of spatial externalities and to estimate their impacts on the regional convergence.

Starting with this new approach, we adopt for our work the following structure:

- $\quad$ The first section will be reserved for developing the model of Mankiew, Romer and Weil (1992) which introduces in the function of production the external effects on the accumulation of production factors (human and physical capital stocks). We suggest that the equation of convergence derived from this model possess similarities with the specifications of spatial models used in spatial econometrics.

- $\quad$ On this base, in the second section, we will chow why these spatial models permit to test better the presence of spatial externalities and to estimate their effects on the economic convergence.

- In the third section, we will expose results of the empirical validation applied on a panel of 26 countries composed by fifteen counties of the European Union and the eleven Mediterranean south counties on the period 1995-2004.

- $\quad$ Finally, in the conclusion, we will resume the interpretations of results.

\section{Model of Mankiw, Romer and Weil (1992)}

In this section, we present the model growth with technological externalities of Mankiw, Romer and Weil (1992).

Formally, the model of M.R.W (1992) incorporates the human capital and physical capital in the function of production:

$$
y_{i t}=\mathrm{A}_{\text {it }} \mathrm{k}_{\mathrm{it}}^{\theta_{\mathrm{k}}} h_{i t}^{\theta_{\mathrm{h}}}
$$

Where, $y_{i t}$ is the level of income in region $\mathrm{i}$ and period $\mathrm{t}, \mathrm{k}_{\mathrm{it}}$ and $\mathrm{h}_{\mathrm{it}}$, the levels of physical capital and human capital and $\theta_{\ell}(\ell=\mathrm{k}, \mathrm{h})$ measures the average internal returns.

The level of technology $\mathrm{A}_{\mathrm{it}}$ in a region $\mathrm{i}$ reflect both an externality within the region $\mathrm{i}$ to investments in $\mathrm{k}$ and the technological interdependence across neighbouring regional economies. We have then,

$$
\mathrm{A}_{i t}=\Delta k_{i t}^{\delta_{k}} h_{i t}^{\delta_{h}}\left(k_{\rho i t}^{\theta_{k}} h_{\rho i t}^{\theta_{h}}\right)^{\gamma}
$$

Where, $\Delta$ is the level of exogenous technology, $\delta_{l} \quad(l=k, h)$ is the measure of external returns within the region to physical and human capital (caused by the effects of the accumulation of these factors in each region) and $\gamma$ measures the effect of spatial externalities between economies, that is assumed to be positive.

From this expression, we can observe that the M.R.W model considers, with a latent manner that the level of technology in a region depends on the accumulation of human capital and physical capital within a region i, but also on the 
accumulation of these factors in the neighbouring regions by the effect of spatial externalities. This chows that this model already predicts, but without demonstrates, that the external effects on the accumulation of factor of production are geographically burned.

Substituting [2] in [1], we obtain:

$$
y_{i t}=\Delta k_{i t}^{\left(\theta_{k}+\delta_{k}\right)} h_{i t}^{\left(\theta_{h}+\delta_{h}\right)} A_{\rho i t}^{\gamma}
$$

From this expression, we deduce a convergence equation, such as the dynamics in the proximity of the steady state is characterised by the following expression. (Note 1):

$$
\begin{aligned}
& g_{y}=\xi-\left(1-e^{-\beta T}\right) \ln y_{0}+\frac{\left(1-e^{-\beta T}\right) \gamma}{1-\left(\tau_{k}+\tau_{h}\right)} \ln y_{0 \rho}+\gamma g_{y \rho}+ \\
& \frac{\left(1-e^{-\beta T}\right)}{1-\left(\tau_{k}+\tau_{h}\right)}\left[\tau_{k}\left(\ln s_{k}-\ln (n+g+d)+\tau_{h}\left(\ln s_{h}-\ln (n+g+d)\right)\right)\right]
\end{aligned}
$$

Where, $\beta=\left(1-\tau_{k}-\tau_{h}\right)(n+g+d)$ is the spread of convergence, $\tau_{k}=\theta_{k}+\delta_{k}, \quad \tau_{h}=\theta_{h}+\delta_{h}$ et $\xi=(1+\gamma) g-\left(1-e^{-\beta T}\right)\left(1-\frac{\gamma}{1-\left(\tau_{k}+\tau_{h}\right)}\right)\left(\ln \Delta_{0}+g T\right)$

Equation [4] expresses that the growth in each region depends on the level of initial income in this region, as well as on the initial level and the growth of income in the neighbouring regions.

\section{Econometric specification}

The expression for growth equation [4] with externalities has much in common with the specifications defined in spatial econometrics. In fact, empirically, externalities across economies translate into dependence across the units of analysis.

Thus, under the assumption that there is information for $\mathrm{N}$ regions and $\mathrm{T}$ time periods, equation [4] could be rewritten as (including a well behaved error term):

$$
g_{y}=\alpha-\left(1-e^{-\beta}\right) \ln y_{0}+\lambda\left(1-e^{-\beta T}\right) W \ln y_{0}+\lambda W g_{y}+\varepsilon
$$

Where, for yearly data, gy denotes annual growth rates, a bold character represents a vector

$\left[\mathrm{N}^{*}(\mathrm{~T}-1) \quad \mathrm{x} 1\right.$ with the information for each region and time period $(\mathrm{t}=2, \ldots, \mathrm{T}$ for $\mathbf{g y}$ and $\mathrm{t}=1, \ldots, \mathrm{T}-1$ for $\mathbf{l n y}) . \mathrm{W} 1 \mathbf{g y}$ and W1Iny are the spatial lags for the growth rates and the initial level of income respectively. $\alpha$ collects any difference in the steady state across economies. It might be composed by variables approaching the factors including in [4]. Finally, $\mathrm{W} 1$ is a $\left[\mathrm{N}^{*}(\mathrm{~T}-1)\right] \mathrm{x}\left[\mathrm{N}^{*}(\mathrm{~T}-1)\right]$ matrix with the following general expression:

$$
W_{1}=\left[\begin{array}{ccccc}
W & 0 & 0 & . & 0 \\
0 & \mathrm{~W} & 0 & . & 0 \\
0 & 0 & \mathrm{~W} & . & 0 \\
\cdot & \cdot & \cdot & \cdot & \cdot \\
0 & 0 & 0 & . & \mathrm{W}
\end{array}\right]
$$

0 being a $(\mathrm{NxN})$ matrix of zeros and $\mathrm{W}$ a $(\mathrm{NxN})$ spatial matrix of weights.

This expression clearly indicates that technological externalities are associated to substantive phenomenon which implies that the growth in a region depends on the initial level of income and the initial and growth of income in 
neighbouring countries. Moreover, this expression explains why the empirical evidence based on the traditional spatial model selection procedure has shown preference for the spatial error specification. It is because the similarity between the expression in (5) and the spatial model of Durbin which derived from the spatial model with autocorrelation in errors.

We note that in the case of equation of convergence the spatial model with autocorrelation in errors is the following:

$$
g_{y}=\alpha-\left(1-e^{-\beta T}\right) \ln y+\varepsilon
$$

$$
\varepsilon=\lambda W_{1} \varepsilon+\mu
$$

Where, $\lambda$ is the parameter that expresses the intensity of spatial dependence between the residues of regression.

That in the spatial model of Durbin is:

$$
g_{. .}=\left(I-\lambda W_{1}\right) \alpha-\left(1-e^{-\beta}\right) \ln v+\lambda W_{1} g_{. .}+\lambda\left(1-e^{-\beta}\right) W_{1} \ln v+\mu
$$

The restrictions in the parameters involving growth rates and the initial conditions match those in our specification, but in the spatial model of Durbin the spatial lag of the variables affecting the steady state (summarised by $\alpha$ in the empirical specification) influences growth rates. If the spatial model of Durbin were to be correct, transitional dynamics for an economy would not only depend on the distance to its own steady-state but also on the distance of the neighbours to their steady state. In contrast, in our model, the latter distance does not exert any direct influence.

\subsection{Definition of weight matrix $W$ :}

The concept of weight matrix constitutes a fundamental element in Spatial Econometrics because it permits to model the interactions between observations. Generally, two principal conceptions are reserved to the determination of the elements of the weight matrix, respectively founded on the principle of contiguity and on the principle of distance.

The matrix of contiguity

The matrix of contiguity reposes on the sharing of a common frontier between spatial unities. Formally, a contiguity matrix represents each localisation of spatial system in line and in column. The "spatial weights" (elements of weight matrix) $w_{i j}$ of matrix of contiguity $\mathrm{W}$ are then defined by the following expression:

$$
w_{i j}= \begin{cases}1 & \text { if regions } \mathrm{i} \text { and } \mathrm{j} \text { are contiguiou } \mathrm{s} \text { for order } 1 . \\ 0 & \text { else. }\end{cases}
$$

Moreover, a same contiguity matrix can represent different arrangements of spatial units (Cliff et Ord, 1981, p. 21). Then, others weight matrices appear useful.

The matrix of distance

The matrix of distance reposes on the idea that two spatial units know high (respectively low) interaction that the distance between them is low (respectively high). Cliff and Ord $(1973,1981)$ are the first ones that used this type of specification, by combining a function of the reverse of the distance that separates two localisations and the relative length of their common frontier. However, recently the most current specifications in the empirical studies use expressions more simple for the spatial weights.

In our work, we carry a simple matrix of distance based on the reverse of the distances that separate spatial units. In this case the elements of this matrix $w_{i j}$ are defined as following:

$$
w_{i j}=1 / d_{i j}
$$

Where $d_{i j}$ is the distance that separate the centroids of countries $\mathrm{i}$ and $\mathrm{j}$.

However, the matrices of weights are standardised in lines for facilitating interpretation of spatial parameters after estimation. Thus, each line $\mathrm{i}$ of matrix of weight $\mathrm{W}$ is divided by the sum of elements $w_{i j}$ that compose it and the resulting spatial weights are: 


$$
w_{i j}^{s}=\frac{w_{i j}}{\sum_{j} w_{i j}}
$$

The standardisation of the matrix of weights permits to compare the spatial parameters issued from different models.

\section{Empirical evidence from the Euro Mediterranean countries}

In this section we estimate the equation of convergence with spatial externalities derived from Mankiw, Romer and Weil (1992) model. We will expose results of empirical validation on a specific sample of Euro Mediterranean countries that is composed from:

1) First, the fifteen countries of the European Union: Germany, France, Italy, Luxembourg, Netherlands, Greece, Spain, Portugal, Ireland, Denmark, Sweden, Finland, Austria, Belgium and United Kingdom.

2) Second, the eleven south Mediterranean countries: Algeria, Tunisia, Cyprus, Egypt, Israel, Lebanon, Jordan, Morocco, Turkey, Syria and Malta.

NB: for the reason of the absence of data availability, the country " Autonomy Palestinian Territory » will be excluded from the analysis.

The period of our analysis is 1995-2004. This period is particularly interesting for the analysis of the impact of spatial externalities on economic convergence, since it corresponds to crescent economic integration between the Euro Mediterranean countries, marked by acceleration of liberalisation of exchanges and by a widening of market. It corresponds also, after the reform of structural founds, to the existence of important regional political aiming to harmonise the potentialities of territories development.

The data that we use in this empirical validation are obtained from "World Indicator Data;W.I.D" version 2006. For panel data, we use thus the variable "growth of labour productivity between $\mathrm{t}$ and $\mathrm{t}-1, \mathrm{t}=2, \ldots, 10$ " as an endogenous variable. Annual data on labour productivity are obtained by dividing yearly data of "GDP at constant price 2000 " by yearly data of "number of population in employment".

Results of spatial dependence tests and results of estimation of spatial models will be plot using the contiguity matrix (equation 8) and distance matrix (equation 9).

\subsection{Estimation of absolute $\beta$-convergence model:}

Although our empirical specification incorporates the spatial dependence, the first step of our empirical work consists to estimate the absolute $\beta$-convergence model without any kinds of spillover:

$$
g_{y}=\alpha-\left(1-e^{-\beta T}\right) \ln y+\varepsilon
$$

\section{Our objective is to determine that the omission of introduction of spatial external effects constitute an insufficiency of absolute $\beta$-convergence model.}

We must note that in case of the estimation of a model with the method of panel data, the model can be with individual fixed effects (Within estimator) or with individual random effects (Estimator with GLS). The choice between these two models is based on the test of Hausman (1978), which is a test for specification of individual effects. The rule of decision of this test is the following: if the realisation of the statistic is higher than $\chi^{2}(\mathrm{~K})$. (Note 2 ) at $\alpha \%$ level (Note 3 ). , we reject the hypothesis null and we privilege the adoption of individual fixed effects and the Within estimator is unbiased. On the contrary, if the statistic of Hausman is smaller than $\chi^{2}(\mathrm{~K})$ at $\alpha \%$ level, we accept the hypothesis null and we privilege the adoption of random individual effects and the use of GLS estimator.

Results of estimation of the equation of convergence under the two specifications of panel are presented in the table 1.

- Results chow that for the two specifications the estimation of the speed of convergence is statistically significant at $5 \%$ level.

- The estimation of the model with random individual effects with the GLS method chows that the speed of convergence is more significant then in the case of the Within estimator (first column), this is explained by the fact that the GLS estimator uses the totality of information (within and between) and not only the intra individual information.

- We note that the test of Fisher is statistically significant indicating that the presence of individual effects. For a level of tolerance of $5 \%$, we remark that the value of the test of Hausman is law and not significant, indicating that the absence of the correlation between the regional specific effects and the explicative variables of model (the hypothesis $\mathrm{H}_{0}: \operatorname{corr}\left(\mu_{i}, X_{i t}\right)=0$ is not rejected). Thus, the estimators of the model with random effects are convergent (Mundlak, 1978). (Note 4). In this sense, we obtain a positive absolute convergence, but slaw because the speed of convergence in 
this model is $2.2 \%$. This value is near to $2 \%$ usually funded in the analysis of international convergence (Barro et Sala-I-Martin, 1995).

\subsection{Diagnostics of spatial dependence}

Spatial diagnostics are provided in table 2. We report five tests for spatial dependence: the Moran's I test, two Lagrange Multiplier tests for spatial error and spatial lag dependence ( $L M L A G, L M E R R)$, and two robust Lagrange Multiplier tests for spatial error and spatial lag dependence (RLMLAG and RLMERR) which are robust to the local presence of the other form of spatial dependence.

Results confirm the presence of spatial dependence in the equation of convergence. This chows that omission of introduction of spatial externalities constitutes an insufficiency of absolute $\beta$-convergence model. Details below explicit this confirmation:

- The first statistic reported is the Moran's I statistic for regression residuals (Cliff and Ord, 1981). This test is for the general presence of spatial dependence (Note 5), and does not allow us to discriminate between the spatial error and spatial lag models. The statistic is significant at the $5 \%$ level for all the standard regressions in Table 1, indicating that the residuals from the a-spatial regressions are spatially autocorrelated and that the standard models are misspecified.

- In order to discriminate between the two forms of spatial dependence (autoregressive spatial model or spatial model with autocorrelation in errors), we follow the decision rule suggested by Anselin and Florax (1995) and consider the Lagrange Multiplier (LM) tests for spatial error and spatial lag dependence and their robust counterparts. The four tests are significant at the $5 \%$ level. The test $L M E R R$ and its robust counterpart RLMERR (for spatial error autocorrelation) are higher than $L M L A G$ and its counterpart robust RLMLAG (for erroneously omitted spatial lag variable). This result chows that the equation of convergence with spatial autocorrelation in errors seems to be the more appropriate specification. In the next step of our work we present results of estimation of this specification.

\subsection{Estimation of absolute $\beta$-convergence model with spatial autocorrelation in errors}

In table 3 , we present results of estimation of absolute $\beta$-convergence model with spatial autocorrelation in errors (equation 6) in the case of random effects, with maximum likelihood method, using the matrix of distance (first column) and the matrix of contiguity (column 2). The interpretation of these results is as following:

- We note a slight increase of speed of convergence that attends $3.1 \%$ with the matrix of distance and $2.7 \%$ with matrix of contiguity. This result suggests that effects of proximity favour slightly the regional convergence process, but the letter remains relatively law.

- The estimation chows strong and positive spatial autocorrelation in error terms: $\hat{\lambda}=0,713$ with the matrix of distance and $\hat{\lambda}=0.614$ with the matrix of contiguity.

- Although the spatial parameter is high and statistically significant, the test of common factor is not significant, showing that the model with spatial autocorrelation in errors can be rewritten as a spatial model of Durbin constraint. (Note 6). This result confirms that our empirical specification (equation 8) resembles to the spatial model of Durbin constraint. On this base, it is than possible to estimate our empirical specification more efficiently, for analysing the impact of spatial externalities on economic convergence in Euro Mediterranean countries.

\subsection{Estimation of empirical specification}

Table 4 resumes results of estimation of the convergence equation with lag endogenous and lag exogenous variables (equation 8) in the case of random effects model, with maximum likelihood method. Interpretation of these results is the following:

- We note that parameters of model are positive and statistically significant and they are higher than values funded in the model with spatial autocorrelation in errors. This confirms that our empirical specification is the most appropriate to analysis the effect of spatial externalities on economic convergence in the Euro Mediterranean space.

- The estimation of this model permit to quantify a double effect of geographic spillovers: first, by the level of growth in neighbouring countries ( $\hat{\lambda}=0.930$ using the matrix of distance and $\hat{\lambda}=0.832$, using the matrix of contiguity). Second, by the level of initial labour productivity in neighbouring countries ( $\hat{\tau}=0.034$ (Note 7 ), using the matrix of distance and $\hat{\tau}=0.026$, using the matrix of contiguity).

This result confirms the theoretical predictions which suppose that the initial level of income in neighbouring countries affects the growth of a country by the effect of pecuniary and technological externalities. This effect can be considered us « supply-side externalities ». Also, growth in a country is high (respectively law), if the growth of neighbouring countries is also high (respectively law). This effect can be related to «demand-side externalities », as a consequence, for instance, of demand from neighbours for final goods or inputs produces in a country.

- $\quad$ Concerning the speed of convergence, we remark that its value doesn't increase significantly after the introduction of spatial externalities, as in the case of spatial model with autocorrelation of errors. 


\section{Conclusions}

In this paper, we analysed the impact of spatial externalities on the economic convergence in the Euro Mediterranean countries. We started by developing the model of Mankwi, Romer and Weil (1992) that introduces externalities between economies due to accumulation of human capital and physical capital. We have deduced from this model an equation of convergence that explains that the convergence to the steady state is related to externalities between countries.

To test the existence of these externalities and estimate their impact on economic convergence we are referred to recent methods of spatial econometrics.

For the empirical validation, relying on a panel of 26 euro méditerranean countrises over the period 1995-2004, we have estimated the equation of convergence with spatial externalities derived from the model of Mankiw, Romer \& Weil (1992). Following specificities of this sample we have exposed our empirical results on the base of contiguity matrix and distance matrix.

We have started our empirical analysis by estimating the absolute $\beta$-convergence model, our aim is to verify if the omission of spatial externalities constitutes an insufficiently of this model. Results of estimation have shown a low speed of convergence that takes value near to $2 \%$ usually funded in the analysis of international convergence (Barro and Sala-I-Martin, 1995). Besides, using the matrix of contiguity and the matrix of distance, the proceeding of research of spatial specification permit to confirm that the empirical specification resembles to the spatial model of Durbin, and thus we estimated our specification more efficiently.

The estimation of this model by the maximum likelihood method has shown that the growth in a country is positively affected by the investments and existents stocks in neighbouring countries. Also, results show that the introduction of spatial externalities hasn't affected the increase of speed of convergence in the Euro Mediterranean area.

These results have lines with theoretical conclusions evoked by "Geography-Growth synthesis" [Baumont and Huriot, 1999]. We think that the economic integration favour dynamic agglomeration by intermediate of regional interactions, but au contrary, the letter strengthens a cumulative agglomeration process.

Therefore, the political integration of markets can't favour the convergence between countries. The diminution of interaction costs (costs of transport and costs of transaction) makes more important the role of localised factors.

This accentuates the weights of initial conditions and contributes to the aggravation of cumulative divergence process and to persistence of diagrams "centre-periphery", that is traduced by a total geographical concentration of R\&D activities and of human capital and by a differentiated repartition of goods and services between countries. The specialisations of nations in innovation or in the fabrication of homogenous and traditional goods are flowed. Thus, the effects of economic integration in the Euro Mediterranean countries have engender an economic divergence process between the north and south countries due to the absence of sufficiently coordinate and interactions between them.

On this base, the efficacy of political integration amid the Euro Mediterranean space in sight of economic convergence will necessitate reinforcement of interactions between the north and south of Mediterranean, for example grace to a best application of Agreements of Barcelona and the New European Political of Neighbourhood and by the application of the proposition of the Union for the Mediterranean.

\section{References}

Abreu M. de Groot H.L.F. and R.J.G.M. Florax. (2005). Space and Growth: A Survey of Empirical Evidence and Methods. Région et Développement, 21, 13-44.

Acs Z and Varga A. (2002).Geography, endogenous growth and innovation. International Regional Science Review 25, 132 - 148 (Special issue on Regional Innovation Systems, edited by Z. Acs and Varga A).

Anselin L. (2001). Spatial Econometrics. In B. Baltagi (Szerk.) A Companion to Theoretical Econometrics. Oxford, Basil Blackwell, 310-330.

Anselin L and Rey SJ. (1991). Properties of tests for spatial dependence in linear regression models. Geographical Analysis, 23: 112-131.

Arbia G, Basile R and Salvatore M. (2003). Measuring spatial effects in parametric and nonparametric modelling of regional growth and convergence. mimeo, Univeristy G. D'Annunzio, Pescara, Italy.

Autant-Bernard et Massard Nadine. (2003)."Innovation and Local Externalities: Evidence and Ambiguities drawn from the Geography of Innovation".Working Paper CREUSET.

Autant-Bernard, C. (2001a). Science and knowledge flows: evidence from the French case. Research Policy, 30(7): 1069-1078.

Baumont C, Ertur C and Le Gallo J. (2001). A spatial econometric analysis of geographic spillovers and growth for 
European Regions, 1980-1995, LATEC - Document de travail - Economie \# 2001-04

Bernard A and Jones C. (1996). Productivity and convergence across U.S. States and industries. Empirical Economics, 21: 113-135.

Carlino G and Mills L. (1993). Are U.S. regional incomes converging? A time series analysis. Journal of Monetary Economics, 32: 335-346.

Chatterji M and Dewhurst J. (1996). Convergence clubs and relative economic performance in Great Britain: $1977-1991$. Regional Studies, 30: 31-40.

Ciccone, A. (1996). Dynamic externalities, spatial technology diffusion, and economic growth, University of California at Berkeley and University Pompeu Fabra, Mimeo. Journal of Common Market Studies, 33: 47-65.

Coe, D., and E. Helpman. (1995). International R\&D spillovers. European International Economic Review, 40, pp. 537-570.

Eaton, J., Kortum, S. (1999). International patenting and technology diffusion'. Economic Review, 39, pp. 859-887.

Fingleton B. (2003). Externalities, economic geography, and spatial econometrics: conceptual and modeling developments. International Regional Science Review, 26: 197-207.

Fingleton B. (2004). Regional economic growth and convergence: insights from a spatial econometric perspective, in Anselin L, Florax R and Rey S (Eds) Advances in Spatial Econometrics, Springer-Verlag, Berlin.

Fingleton B and López-Bazo. (2005). Empirical growth models with spatial effects. Manuscript.

Fingleton, B. and J.S.L. McCombie. (1998). Increasing returns and economic growth: Some evidence for manufacturing from the European Union regions. Oxford Economic Papers, 50, 89-105.

Florax, R. and H. Folmer. (1992). Specification and estimation of spatial linear regression models: Monte Carlo evaluation of pre-test estimators. Regional Science and Urban Economics, 22, pp. 404-432.

Keller, J. (1997). Are international R\&D spillovers trade-related? Analyzing externalities. Economics Letters, 53, pp. 227-232.

Le Gallo J. Ertur C. and Baumont C. (2003). A spatial econometric analysis of convergence across European regions, 1980-1995. In: Fingleton B (ed) European regional growth. Springer, Berlin, pp 99-129.

Le Gallo J. (2000). Econométrie spatiale 1 : Autocorrélation spatiale, document de travail du LATEC n²000-05, Université de Bourgogne, Dijon.

León-Ledesma MA. (2000). Economic growth and Verdoorn's law in the Spanish regions. International Review of Applied Economics, 14: 55-69.

López-Bazo E, Vayá E and Artís M. (2004). Regional externalities and growth: evidence from European regions. Journal of Regional Science, 44: 43-73.

López-Bazo E, Vayá E, Mora A, Suriñach J. (1999). Regional economic dynamics and convergence in the European union. Annals of Regional Science, 33: 343-370.

Mankiw, N.G., Romer, D. and D.N. Weil. (1992). A contribution to the empirics of economic growth, Quarterly Journal of Economics, 107, pp. 407-437.

Park, W.G. (1995). International R\&D spillovers and OECD economic growth. Economic Inquiry, 33, pp. 571-591.

Quah, D. (1996).Regional convergence clusters across Europe. European Economic Review, 40, pp. 951-958.

Raut, L.L. (1995). R\&D spillovers and productivity growth: evidence from Indian private firms. Journal of Development Economics, 48, pp. 1-23.

Ravallion, M. and J. Jalan. (1996). Growth divergence due to spatial externalities. Economics Letters, 53, pp. $227-232$.

Ravallion, M. and J. Jalan. (1996). Growth divergence due to spatial spillovers among randomly matched trade partners", National Bureau of Economic Research, nº 6065, Cambridge MA.

Rey, S.J., Montouri, B.D. (1999). U.S. regional income convergence: a spatial econometric perspective. Regional Studies, 33, 145-156.

Temple, J. (1999). The new growth evidence. Journal of Economic Literature, 37, 112-156.

Varga A. (2000). Local academic knowledge spillovers and the concentration of economic activity. Journal of Regional Science, 40, 289-309.

Varga A and Schalk H. (2004). Knowledge spillovers, agglomeration and macroeconomic growth. An empirical approach. Regional Studies, 38, 977-989. 


\section{Notes}

Note 1. Details on this transformation of convergence equation are given in the paper of López-Bazo E, Vayá E and Artís M (2004); Regional externalities and growth: evidence from European regions, Journal of Regional Science 44: 43-73.

Note 2. This is the number of freedom or also the number of exogenous variables.

Note 3 . This value is obtained from the table of $\chi^{2}$

Note 4. Details on the model with random effects and spatial dependence are presented in apendex .

Note 5. The test of Moran doesn't specify the alternative hypothesis for the absence of spatial autocorrelation.

Note 6. The test of the constraint of parameters is done with the test of ratio likelihood of common factor (Burridge, 1981).

Note 7. $\hat{\tau}=\hat{\lambda}\left(1-e^{-\hat{\beta}}\right)$

Table 1. Estimation of absolute $\beta$-convergence model (equation 11)

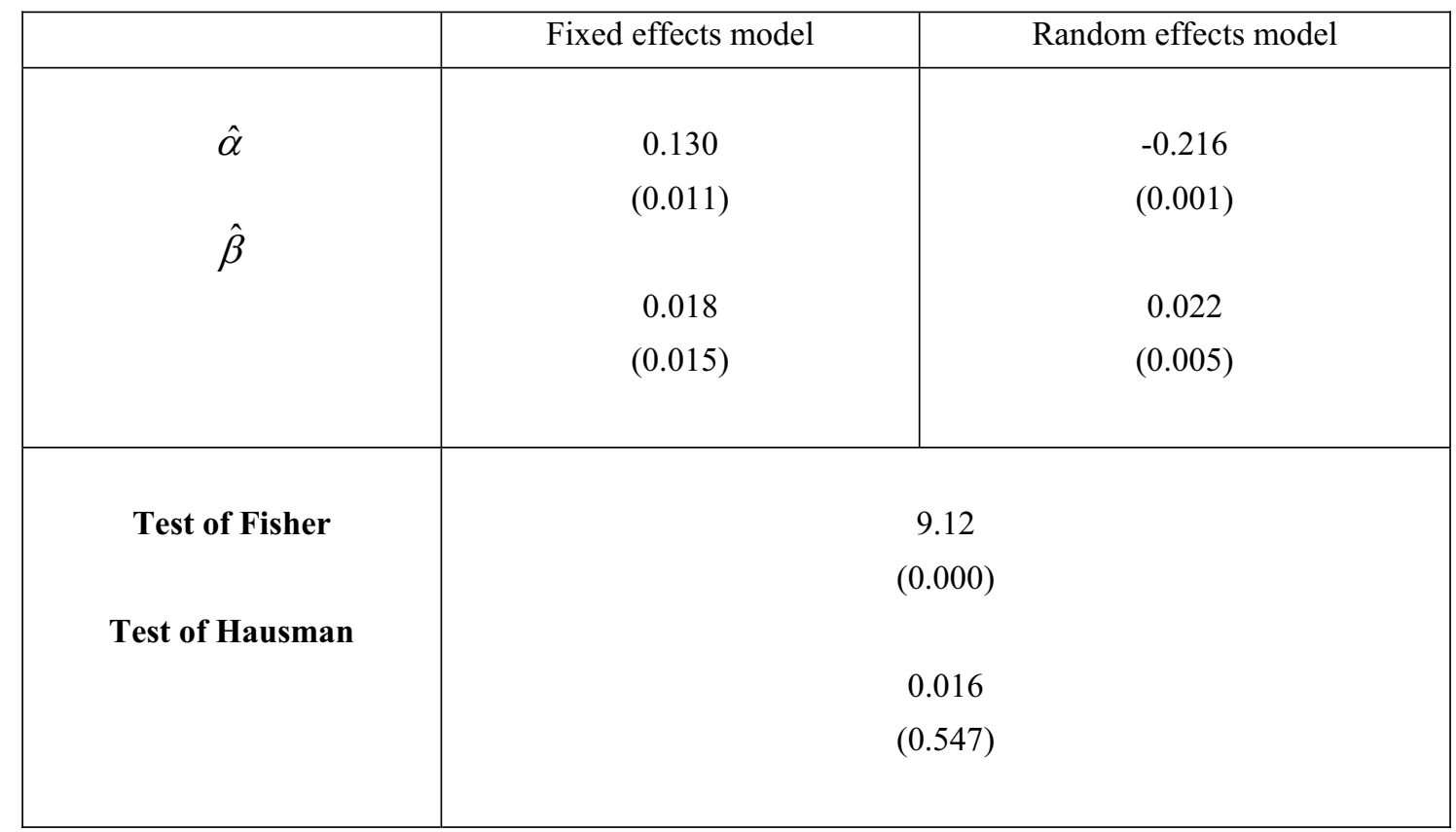

Note: $\mathrm{N}=26, \mathrm{~T}=10$; the values of critical probabilities are between parentheses.

Level of significantly $=5 \%$ 
Table 2. Tests of spatial dependence in absolute $\beta$-convergence model

\begin{tabular}{|c|c|c|}
\hline Tests & Distance matrix & Contiguity matrix \\
\hline \multirow{2}{*}{ MORAN } & 532.251 & 302.642 \\
& $(0.000)$ & $(0.000)$ \\
& 914.313 & 716.415 \\
& $(0.000)$ & $(0.000)$ \\
LMLAG & 641.632 & 402.637 \\
& $(0.000)$ & $(0.000)$ \\
RLMERR & 509.562 & 399.533 \\
& $(0.000)$ & $(0.000)$ \\
& & 202.222 \\
& 299.088 & $(0.000)$ \\
\hline
\end{tabular}

Note: The values of critical probabilities are between parentheses. Level of significantly $=5 \%$.

Table 3. Estimation of absolute $\beta$-convergence model with spatial dependence in errors: (equation 6)

\begin{tabular}{|c|c|c|}
\hline & Distance matrix & Contiguity matrix \\
\hline$\hat{\alpha}$ & 0.542 & 0.891 \\
$\hat{\beta}$ & $(0.001)$ & $(0.004)$ \\
$\hat{\lambda}$ & & 0.027 \\
& 0.031 & $(0.003)$ \\
& $(0.002)$ & 0.614 \\
& 0.713 & $(0.001)$ \\
Test of common factor & $(0.001)$ & \\
& & 0.031 \\
& & $(0.759)$ \\
& 0.035 & \\
\hline
\end{tabular}

Note: $\mathrm{N}=26, \mathrm{~T}=10$; Estimation by Maximum Likelihood method. The values of critical probabilities are between parentheses. Level of significantly $=5 \%$ 
Table 4. Estimation of empirical specification (equation 5)

\begin{tabular}{|c|c|c|}
\hline & Distance matrix & Contiduity matrix \\
\hline$\hat{\alpha}$ & -0.645 & -0.495 \\
$\hat{\beta}$ & $(0.002)$ & $(0.004)$ \\
& & \\
$\hat{\lambda}$ & 0.038 & 0.032 \\
& $(0.003)$ & $(0.003)$ \\
$\hat{\tau}=\hat{\lambda}\left(1-e^{-\hat{\beta}}\right)$ & 0.930 & 0.832 \\
& $(0.001)$ & $(0.003)$ \\
& & 0.026 \\
& 0.034 & $(0.001)$ \\
& $(0.001)$ & \\
\hline
\end{tabular}

Note: $\mathrm{N}=26, \mathrm{~T}=10$; Estimation by Maximum Likelihood method. The values of critical probabilities are between parentheses. Level of significantly $=5 \%$.

\section{APENDEX}

\section{Random effects model and spatial dependence}

The spatial autocorrelation can be incorporated in the random effects model in which the coefficients of regressions are supposed fixed (Anselin, 1988a ; Case, 1991 ; Baltagi et Li, 2002). In this model we have:

$y_{i t}=x_{i t}^{\prime} \beta+\varepsilon_{i t} \quad \mathrm{i}=1, \ldots \mathrm{N} ; \mathrm{t}=1, \ldots ., \mathrm{T}$

Where $y_{i t}$ is a vector $N T \times 1, i$ denotes the region and the period, $x_{i t}$ is a vector $k \times 1$ of observations relative to $k$ explicative variables and $\beta$ is a vector $k \times 1$ of parameters.

The term of error is supposed to incorporate the unobservable effects due to space (Hsiao, 1986; Baltagi, 1995):

$$
\varepsilon_{i t}=\mu_{i}+\phi_{i t} \quad \mathrm{i}=1, \ldots \ldots \mathrm{N} ; \mathrm{t}=1, \ldots ., \mathrm{T}
$$

$\mu_{i}$ is a vector $N \times 1$ of regional specific effects. The vector $N T \times 1$ of error terms $\phi_{i t}$ with mean null and variance $\sigma_{\varepsilon}^{2}$, is supposed normal, $\phi_{i t} \sim \mathrm{N}\left(0, \sigma_{\varepsilon}^{2}\right)$. The $\phi_{i t}$ are supposed independents of effects $\mu_{i}$ and explicative variables of model.

\section{The autoregressive spatial model:}

A first formulation of spatial dependence is the specification of autoregressive spatial model (cf. Florax et Folmer, 1992). If we consider an impalement of $T$ observations relative to each region, the random effects model with spatial dependence can be written under the following form:

$$
Y=\rho W^{1} Y+X \beta+Z \mu+\phi
$$

Where $Z=\left(I_{N} \otimes l_{T}\right)$ is a $N T \times N$ matrix of regional indicative variables, $l_{T}$ is a vector $T \times 1$ of 1 . The sign $\otimes$ is the kronecker product. $W^{l}=\left(W_{N} \otimes I_{T}\right)$ where $W_{N}$ is the $N \times N$. spatial weight matrix, standardized. $\rho$ is the spatial autoregressive coefficient.

The matrix of variances in the case of spatial autoregressive model presents the following structure:

$$
\Omega\left(\rho, \theta_{1}^{2}, \sigma_{\varepsilon}^{2}\right)=\sigma_{\varepsilon}^{2} M^{-1}(\rho)\left[Q+\theta_{1}^{-2} B\right] M^{\prime^{-1}}(\rho)
$$


Where $M(\rho)=\left(I_{N T}-\rho W_{1}\right), B=\left(I_{N} \otimes T^{-1} l_{T} l_{T}^{\prime}\right)$ and $Q=\left(I_{N T}-B\right)$ are respectively the $N T \times N T$ operators between and within and $\theta_{1}^{2}=\frac{\sigma_{\varepsilon}^{2}}{T \sigma_{\mu}^{2}+\sigma_{\varepsilon}^{2}}$.

The determinant and the reverse of $\Omega$ are respectively:

$$
\begin{aligned}
& |\Omega(.)|=\sigma_{\varepsilon}^{2}|M|^{2}\left|\theta_{1}^{2}\right|^{-T} \\
& \text { And } \quad \Omega^{-1}(.)=\sigma_{\varepsilon}^{-2} M_{1}^{\prime}\left[Q-\theta_{1}^{2} B\right] M_{1}
\end{aligned}
$$

\section{Spatial model with autocorrelation in errors:}

A second formulation of spatial dependence supposes that the errors $\phi_{i t}$ are spatially autocorrelated (cf. Florax et Folmer, 1992; Baltagi et Li, 1999):

$$
\phi=\lambda W \phi+v
$$

Where $\lambda$ is the coefficient of spatial autocorrelation. It catches the effects of spatial variables omitted in the model. The vector $N T \times 1$ of errors $v_{i t}$ is supposed normal, $v_{i t} \sim \mathrm{N}\left(0, \sigma_{v}^{2}\right)$. $v_{i t}$ are also supposed independents of the effects $\mu_{i}$ and the explicative variables of model.

In the case of spatial model with autocorrelation in errors, the matrix of variances possesses the following structure:

$$
\Omega\left(\lambda, \theta_{2}^{2}, \sigma_{v}^{2}\right)=\sigma_{v}^{2}\left\lfloor Q+\theta_{2}^{-2} B+\left(M^{\prime}(\lambda) M(\lambda)\right)^{-1}-I_{N T}\right\rfloor
$$

Where, $\theta_{2}^{2}=\frac{\sigma_{v}^{2}}{T \sigma_{\mu}^{2}+\sigma_{v}^{2}}, M(\lambda)=\left(I_{N T}-\lambda W_{1}\right)$

The determinant and the reverse of the matrix $\Omega($.$) can be written respectively ( c f$. Anselin, 1988 : 153-154) :

$$
\begin{aligned}
& \qquad|\Omega(.)|=\sigma_{v}^{2}\left|A_{N}\right|^{-2(T-1)}\left|\left(A_{N}^{\prime} A_{N}\right)^{-1}+\left(\theta_{2}^{-2}-1\right) I_{N}\right| \\
& \text { and } \Omega^{-1}(.)=\sigma_{v}^{-2}\left\{\left(A_{N}^{\prime} A_{N}\right) \otimes\left(I_{T}-\bar{J}_{T}\right)+\left[\left(A_{N}^{\prime} A_{N}\right)^{-1}+\left(\theta_{2}^{-2}-1\right) I_{N}\right]^{-1} \otimes \bar{J}_{T}\right\}
\end{aligned}
$$

where, $A_{N}=I_{N}-\lambda W$

\section{Estimation by the maximum likelihood method:}

The application of Ordinary Least Square (OLS) or Generalised Least Square (GLS) methods for estimation of models with spatial dependence leads to biased and not convergent estimators (cf. Dubin, 1988; Florax et Folmer, 1992). An appropriated method of estimation is the maximum likelihood (ML) (Anselin, 1988: 57-59).

The expression of log likelihood with spatial dependence is the following:

$$
L\left(\alpha, \beta, \theta_{j}^{2}, \sigma^{2}\right)=c_{0}-\frac{N T}{2} \ln \left|I_{N T}-\alpha W_{1 N T}\right|-\frac{1}{2} u^{\prime} \Omega^{-1}\left(\alpha, \theta_{j}^{2}, \sigma^{2}\right) u
$$

$c_{0}=-N T \ln (2 \pi) / 2$

We deduce the autoregressive spatial model for $\alpha=\rho, \mathrm{j}=1, \sigma^{2}=\sigma_{\varepsilon}^{2}$ and $u=M(\rho) Y-X \beta-Z \mu$. And the spatial model with autocorrelation in errors for $\alpha=\lambda, \mathrm{j}=2, \sigma^{2}=\sigma_{v}^{2}$ and $u=M(\lambda)(Y-X \beta-Z \mu)$.

The estimation of models with spatial dependence with the likelihood method necessitates an no linear optimisation and implies numeric calculations as mach harder and longer when the number of observations is important. In particular, 
one of difficulties in application of the ML resides in calculation of determinant of the Jacobean. An alternative proposed by Ord (1975) reposes on proper values of the weight matrix. Then,

$$
\left|I_{N T}-\alpha W_{1 N T}\right|=\left|I_{N}-\alpha W_{N}\right|=\prod_{i}\left(1-\alpha w_{i}\right)
$$

Where the $\omega_{i}$ design the proper values of the matrix $W_{N}$ and $\alpha=\{\rho, \lambda\}$. The identity [12] implies that the values of coefficients of spatial dependence must satisfy the condition: $\omega_{\min }^{-1} \leq \alpha \leq \omega_{\max }^{-1}$ where $\omega_{\max }=1$ in the case of weight matrices normalised. The advantage of this procedure is that we can determine the proper values of these matrices before the optimisation (since $W_{N}$ is supposed known). This reduces considerably the numeric calculation of likelihood of model, at least in the case of small samples. 